\title{
Análise da Resiliência entre Pessoas que Vivem com HIVIAIDS: Um Estudo Psicossocial
}

\author{
Ludgleyson Fernandes de Araújo 1,* (D, Bruno de Sousa Leal', \\ José Victor de Oliveira Santos ${ }^{1}, \&$ Alice Vitória Cordeiro Sampaio ${ }^{2}$ \\ ${ }^{1}$ Universidade Federal do Piauí, Parnaíba, PI, Brasil \\ ${ }^{2}$ Faculdade Internacional do Delta, Parnaiba, PI, Brasil.
}

\begin{abstract}
RESUMO - A presente investigação teve como objetivo principal estudar os processos psicossociais da resiliência entre as pessoas que convivem com o HIV. Trata-se de uma pesquisa transversal com dados qualitativos que foi realizada com 44 pessoas em acompanhamento no Centro de Testagem e Aconselhamento de Parnaíba- Piauí. Os resultados mostraram alguns fatores de risco e, também, de proteção, tais como preconceito e exclusão, dificuldades de iniciar o tratamento antirretroviral, complicações do uso dos medicamentos e importância do apoio social para que haja diminuição dos fatores de risco e melhor predisposição ao desenvolvimento da resiliência. Foi concluído que fatores psicossociais podem predispor os indivíduos ao maior desenvolvimento do processo de resiliência.
\end{abstract}

PALAVRAS-CHAVE: resiliência, hiv, pacientes

\section{Analysis of Resilience among People Living with HIVIAIDS: A Psychosocial Study}

\begin{abstract}
The main objective of the present research was to study the psychosocial processes of resilience among people living with HIV. It is a cross-sectionalresearch with qualitative data that was carried out with 44 people in treatment at the Testing and Counseling Center of Parnaíba-Piauí. The results showed some risk and protection factors, such as prejudice and exclusion, difficulties in initiating antiretroviral treatment, complications in using prescribed drugs, and the relevance of social support to reduce risk factors and promote better predisposition to development. of resilience. It was concluded that psychosocial factors may predispose individuals to a greater development of the resilience process.
\end{abstract}

KEYWORDS: resilience, hiv, patients

O HIV (vírus da imunodeficiência humana) foi identificado, em 1980, como um vírus do grupo de retrovírus que, ao agir sobre o sistema imunológico, destrói todas as defesas do organismo, tornando o corpo humano suscetível a doenças que, nesse caso, são denominadas de doenças oportunistas (Araújo, 2014; Freitas, Santos, \& Araújo, 2019). Até o final de 2018 havia cerca de 37,9 milhões de pessoas vivendo com HIV no mundo, sendo que se apresentaram 2 milhões de novos casos com diagnóstico positivo e 1,7 milhões de mortes por doenças relacionadas com o HIV nesse mesmo período, de acordo com o Programa Conjunto das Nações Unidas sobre HIV/AIDS (ONUSIDA, 2019).
Desde o ano de 1980 até junho de 2018 foram notificados aproximadamente 982.129 casos de AIDS no Brasil, sendo a prevalência dos casos maior nos homens $(68,6 \%)$ do que nas mulheres $(31,4 \%)$. Há uma relação de 26 casos em homens para cada 10 casos em mulheres e maior concentração nos indivíduos entre 20 e 34 anos de idade. Existe a previsão de aumento nessa faixa de idade e nas faixas de 20 a 29 anos e 30 a 39 anos, com manutenção da prevalência maior entre pessoas do sexo masculino comparadas às do sexo feminino (Ministério da Saúde, 2018).

O aumento das infecções pelo HIV deve-se às condutas sexuais de risco, como: a falta do uso de preservativos,

*E-mail: ludgleydson@yahoo.com.br

- Submetido: 23/09/2016; Revisado: 21/02/2018; Aceito: 15/03/2018. 
abuso de substâncias psicoativas e relações sexuais com múltiplos parceiros ao longo da vida. Além disso, pessoas que se sentem expostas aos riscos têm menores chances de se envolver nos comportamentos sexuais de risco, enquanto pessoas que não se sentem em risco têm maiores chance de se engajar nesses comportamentos (Kline, 2014).

As condutas sexuais de risco, aliadas à diminuição do medo das pessoas de infectar-se com o HIV após a utilização dos medicamentos antirretrovirais (TARV), têm influenciado o aumento dos casos de infecções, sobretudo entre os jovens (15 a 25 anos) e os homossexuais. Ademais, houve também um aumento do uso de profilaxia pré-exposição (PrEP) como um meio de prevenção da infecção pelo HIV, indicado principalmente para algumas populações, o que pode exacerbar o preconceito sobre determinados grupos (Araújo, 2014; Araújo, Lôbo, Santos, \& Sampaio, 2017; Freitas et al., 2019).

Em decorrência do aumento no número de infecções pelo HIV, faz-se necessário o estudo da resiliência, um construto que pode ser utilizado tanto na prevenção da infecção do HIV, diminuindo os comportamentos sexuais de riscos, quanto na vivência da infecção, contribuindo para a qualidade de vida mesmo após o surgimento das adversidade causadas pela infecção do vírus.

A resiliência é um construto originado da Física, em que era feita a analogia com materiais, como se fossem elásticos, por terem a capacidade de voltarem às suas formas originais mesmo após passar por deformações (Araújo, Teva, \& Bermúdez, 2015). Esse construto foi levado para o campo das ciências humanas e psicológicas, mas até hoje não há um consenso sobre a definição de resiliência, a qual que se baseia em três perspectivas diferentes: (1) a capacidade de adaptação frente a um problema, (2) a capacidade de superar um trauma e (3) a capacidade de lidar com situações estressantes (Luthar, Ciccheti, \& Becker, 2000).

Resiliência é também um processo dinâmico, que visa uma adaptação positiva frente a um contexto de dificuldade, levando em conta que para que exista resiliência é necessária a exposição a uma ameaça significativa ou de grande adversidade (Luthar et al., 2000). De acordo com estudos mais recentes, esse construto refere-se não apenas a propriedades individuais, mas também a múltiplas expressões e interações interpessoais, sociais, históricas, além de fatores genéticos e epigenéticos, visto que até mesmo catástrofes e doenças podem surgir como eventos estressores e exigirem adaptação para a sobrevivência (Bhui, 2014).
No contexto da resiliência em pessoas que vivem com HIV, há poucos estudos, e dentre esses, destaca-se aquele realizado por de Santis, Florom-Smith, Vermeesch, Barroso, e de Leon (2013), que abordou a elaboração de uma teoria com base qualitativa que descreva como ocorrem os processos subjetivos da resiliência em pessoas que vivem com HIV, por meio dos próprios viventes, chegando a motivações intrínsecas (e.g., senso de espiritualidade, desejo de sobreviver e desejo de conhecimento sobre a infecção) e motivações extrínsecas (e.g., vontade de revelar o diagnóstico de infecção, desejo de apoio psicossocial e gestão da doença), entre outros aspectos.

Bezerra (2015) se propôs, ao estudar resiliência, a estabelecer uma relação com a qualidade de vida, dando enfoque aos aspectos individuais, que a autora chama de traços de personalidade, e ao meio social, no qual a autora discute a importância do suporte social como fator de proteção. Outro estudo que fala sobre a resiliência em pessoas com HIV/AIDS é o de Lima, Pichelli e Silva (2014), no qual é investigada a convivência com o HIV/AIDS entre mulheres, levando em conta a adesão ao tratamento, as formas de enfrentamento, o preconceito, dentre outras características. Santos (2016) também trabalhou com a perspectiva do HIV/AIDS em mulheres, com ênfase nos fatores de risco, nos fatores protetivos e na resiliência nessa população. Araújo (2014), por sua vez, abordou os construtos de autoeficácia, resiliência, preocupação por infecções de transmissão sexual, entre outros, em pessoas que vivem com HIV, fazendo uma comparação com indivíduos da população em geral que não vivem com o vírus.

Diante do pequeno número de publicações sobre resiliência em pessoas que vivem com HIV, o presente estudo visa contribuir para ampliar e encorajar as investigações sobre o tema, o qual apresenta grande relevância social. Isso porque esse construto demonstra ser fundamental como forma de enfrentamento do estigma e da depressão, que são dois pontos que ainda perpassam pela vida dessas pessoas, uma vez que ainda há muita discriminação voltada para pessoas diagnosticadas com o HIV (Araújo, 2014; Castro, Santos, Araújo, Faro, Rocha, \& Reis, 2019). Sendo assim, a presente investigação teve como objetivo principal estudar os processos psicossociais da resiliência entre as pessoas que convivem com o HIV. Para tanto, foi realizada uma pesquisa transversal com aspectos qualitativos. Nesse tipo de pesquisa, o objetivo consiste em investigar possíveis relações entre um determinado fato identificado pelo pesquisador e um fenômeno que ocorre posteriormente (Martins \& Ramos, 2013), com a utilização de dados transversais.

\section{MÉTODO}

\section{Participantes}

Os critérios de inclusão para a participação na pesquisa foram: ter idade acima de 18 anos, apresentar diagnóstico de infecção pelo vírus do HIV e estar em acompanhamento pelo CTA. Com base nesses critérios, os pacientes eram encaminhados pelos profissionais do CTA aos pesquisadores responsáveis. Houve recusa de cerca de $20 \%$ dos participantes 
por diversos motivos, tais como disponibilidade de tempo, não conseguirem expor $\mathrm{o}$ assunto etc.

A amostra foi composta por 44 pessoas vivendo com o HIV/AIDS, de ambos os sexos, sendo a grande maioria do sexo masculino (58,8\%), com Ensino Fundamental incompleto $(41,2 \%)$, heterossexuais $(78,4 \%)$, com idade de 23 a 67 anos $(M=41, D P=10,6)$, com renda de menos de um salário mínimo $(41,2 \%)$ ou com um salário mínimo $(41,2 \%)$, solteiros (54.9\%), diagnosticados entre 2006-2010 (27,5\%) e com o número de pessoas que sabem da sua infecção pelo HIV de 1 a 5 pessoas $(41,2 \%)$, todos em acompanhamento no Centro de Testagem e Aconselhamento (CTA) da Secretária da Saúde da Prefeitura Municipal de Parnaíba/PI, Brasil.

\section{Local}

A pesquisa foi realizada em uma sala do Centro de Testagem e Aconselhamento (CTA) na cidade de ParnaíbaPiauí, com a permissão dos coordenadores responsáveis.

\section{Instrumentos}

Foi utilizado o Questionário sobre Dados Sociodemográficos, o qual envolvia perguntas sobre sexo, idade, escolaridade, estado civil, renda, orientação sexual, existência de parceira(o) ou não, ano de diagnóstico, contaminação por alguma infecção sexualmente transmissível - IST, conhecimento de como foi infectado. Foi também utilizado o Questionário sobre Condutas Sexuais, por meio do qual buscou-se identificar as condutas sexuais praticadas pelos participantes da pesquisa, tais como o uso de camisinha nas primeiras relações sexuais vaginais e anais, número de parceiros sexuais ao decorrer da vida, dentre outras. Por fim, foi utilizada a Pergunta sobre Resiliência ("Quais as principais dificuldades encontradas por alguém que vive com o $H I V$ ') com a finalidade de identificar as principais dificuldades vivenciadas pelas pessoas que convivem com o HIV, verificando, assim, as formas como a resiliência se dá nessas pessoas.

\section{Procedimento}

Após aprovação do Comitê de Ética em Pesquisa da Universidade Federal do Piauí no Campus Ministro Reis Velloso-CMRV (número do CAAE: 48518815.2.0000.5669) e a assinatura do Termo de Consentimento Livre e Esclarecido, foi iniciada a coleta de dados por meio da aplicação dos instrumentos. Os próprios participantes responderam ao questionário, individualmente, sendo que um deles preferiu expor suas respostas de forma oral enquanto um dos pesquisadores responsáveis realizava a transcrição dessas respostas.

\section{Análise de Dados}

Os dados coletados foram inseridos em uma base de dados no software estatístico SPSS 25, para a realização das análises descritivas do Questionário sobre Dados Sociodemográficos e do Questionário sobre Condutas Sexuais. Os dados coletados por meio da Pergunta sobre Resiliência foram inseridos na base de dados do programa IRAMUTEQ.

As respostas aos instrumentos foram agrupadas em um corpus, construído com as respostas dos 44 participantes a uma pergunta aberta. A resposta correspondeu a um texto e este foi separado por linhas de comando, que são informações codificadas, separadas por asteriscos, indicando o número de identificação do participante (n), o sexo (masculino $=1$; feminino $=2$ ), a idade (entre 23 e 30 anos $=1$; entre 31 e 38 anos $=2$; entre 39 e 46 anos $=3$; entre 47 e 54 anos $=4$; de 55 anos acima $=5$ ), o estado civil (solteiro $=1$; casado $=2$; separado $=3$; viúvo $=4 ;$ outro $=5$ ), o ano de diagnóstico (entre 1985 e $1990=1$; entre 1991 e $1995=2$; entre 1996 e $2000=3$; entre 2001 e 2005=4; entre 2006 e 2010=5; entre 2011 e 2014 6 ; de 2015 acima $=7$ ), e a orientação sexual (heterossexual $=1$; homossexual $=2$; bissexual $=3$; e outro $=4$ ), assumindo a forma abaixo exemplificada:

$$
* * * * \text { n_001 } * \text { sex_1 } * \text { idad_4 } * \text { estd_1 } * \text { diag_ } 4 * \text { orient_2 }
$$

Foram realizados três tipos de análises para o corpus. Primeiro, foi feita a Classificação Hierárquica Descendente (CHD), que classifica o conteúdo dos textos baseado na frequência e qui-quadrado $\left(\mathrm{X}^{2}\right)$, criando classes de Unidades de Contextos Elementares (UCEs) com vocabulário semelhante entre si e, ao mesmo tempo, diferente das UCEs das demais classes. Essas classes, nomeadas e descritas a partir do tema do estudo, são representadas por dendogramas, que ilustram as relações entre elas (Camargo, 2005).

Em seguida, foi realizada a análise de Nuvem de Palavras, que agrupa as palavras em função da frequência e exibe o resultado de forma gráfica. E, finalmente, a Análise de Similitude, que apresenta um desenho indicando a conexão entre as palavras, pelo qual é possível identificar as coocorrências destas.

\section{RESULTADOS E DISCUSSÃO}

Os resultados da entrevista semiestruturada sobre resiliência entre pessoas que vivem com HIV foram descritos em uma única parte ou corpus textual. A CHD do corpus foi obtida a partir das respostas às perguntas, referentes às 
opiniões dos participantes sobre as dificuldades enfrentadas ao viverem com infecção pelo HIV. O corpus foi formado por 44 Unidades de Contexto Inicial (UCI) e dividido em 29 UCEs.

No dendograma foram descritas as quatro classes que compunham o corpus, sendo a primeira classe denominada de "Exclusão social e preconceito", a segunda classe, de "Aspectos biológicos da infecção pelo HIV", a terceira classe, de "Necessidade de suporte na infecção pelo HIV" e a quarta classe, de "Desafios pelo início da infecção pelo $H I V$ '. Cada classe inclui o título e a descrição de cada uma delas, o número de UCEs que a compõem, as variáveis descritivas e as palavras que mais se associam com a classe em questão, considerando o coeficiente do teste de $\operatorname{associação~}_{\mathrm{x}}^{2}$ (ver Figura 1).

\section{Classe I: Exclusão Social e Preconceito}

A primeira classe é ilustrada na fala dos participantes, principalmente, pela dificuldade em conseguirem meios de subsistência a partir do trabalho laboral e pelo preconceito que está atrelado ao vírus do HIV, muitas vezes, ocasionado pela falta de informação acerca das formas de contágio, o que pode ser exemplificado pelo relato a seguir:

Dificuldade de arranjar trabalho, pois há muito preconceito e ao descobrir que a gente tem o vírus podemos ainda perder o emprego quando arranjamos, além de nos olhar diferente como se a gente não existisse mais para a sociedade quando descobrem. (sexo feminino, idade entre 39 e 45 anos)

No relato da participante fica nítido o estigma social ainda vivido pelas pessoas infectadas pelo HIV, pois ilustra um pouco do desconhecimento dos indivíduos sobre as formas de contágio e sobre as formas de tratamento, o que suscita, nos infectados, um medo de ser exposto. No entanto quando há a aceitação do seu diagnóstico por fatores individuais, sociais e familiares, há a possibilidade delas se tornarem mais resilientes e persistirem apesar desse forte estigma e preconceito vivido (Araújo, 2014; de Santis et al., 2013).

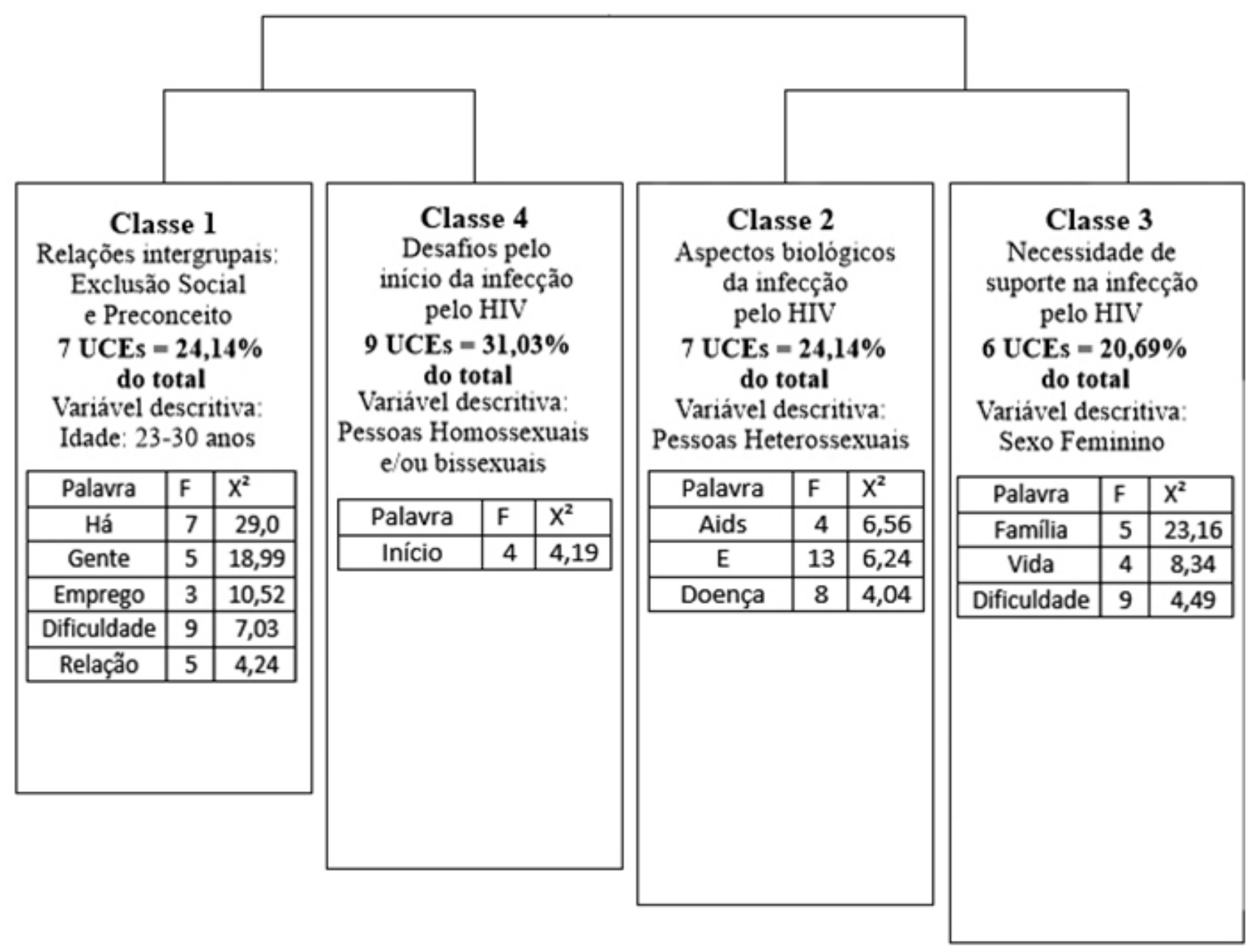

Figura 1. Dendograma da classificação hierárquica descendente da resiliência em pessoas com HIV. 
Como tentativa de enfrentamento desse estigma e exclusão social foi criada a Lei $\mathrm{n}^{\circ} 12.984$, de 2 de junho de 2014 (Presidência da República, 2014), que dispõe que é estritamente proibido discriminar e divulgar a condição de soroposidade da pessoa com o intuito de ofender a sua dignidade, e negar-lhe trabalho e/ou demiti-lo pela sua condição sorológica. Essas ações ainda são frequentes e ficam, muitas vezes, sem a punição estabelecida pela lei (um a quatro anos de reclusão), mostrando, assim, o descaso e o preconceito ainda muito arraigado contra pessoas infectadas pelo vírus do HIV. É de fundamental importância que todas as pessoas que convivem com o HIV tenham conhecimento dessa lei, pois tal conhecimento funciona como um fator protetivo diante da infecção pelo HIV, contribuindo para a própria autoeficácia no exercício de seus direitos. Esse aspecto é crucial uma vez que o trabalho é um importante fator preceptor de resiliência, podendo contribuir diretamente para a saúde mental (Araújo et al., 2017; Costa, Souza, Ribeiro, Santos, \& Carneiro,2014; Lima, Pichelli, \& Silva, 2014;).

A exclusão social de pessoas infectadas pelo vírus do HIV ainda é grande, podendo ser ilustrada pelo fato de que 46 países ainda impõem alguma forma de restrição para a entrada dessas pessoas, como Cuba, Rússia e Austrália, e cinco países proíbem totalmente a entrada de pessoas infectadas pelo HIV, como Egito, Iraque, Singapura, Catar e as ilhas britânicas Turks e Caicos. Em alguns países, a entrada só começou a ser permitida recentemente, como nos Estados Unidos, China e Ucrânia, aumentando assim o leque de lugares onde essas pessoas poderiam visitar ou residir. No entanto, mesmo com a abertura desses países, ainda há muitos que se encontram fechados, demonstrando a forte exclusão social e preconceito ao qual indivíduos com HIV estão submetidos (Agência Aids, 2012).

A variável descritiva dessa classe é a idade entre 23 e 30 anos que está dentro da faixa etária que contém o maior número de pessoas infectadas pelo HIV, principalmente entre os homens. No entanto, essa é uma faixa etária que possui uma sobrevida maior em relação às pessoas com mais idade, além de que ainda é composta por uma população ativa que faz planos e pensa, principalmente, em acender profissionalmente e, até mesmo, em constituir família. Dado esse interesse de participação no trabalho, os indivíduos dessa faixa etária estão em contato constante com as dificuldades do mercado de trabalho, contudo, essa perspectiva de futuro é um importante fator de predisposição da resiliência (Oliveira, Negra, \& Martins, 2012).

\section{Classe 4: Desafios pelo Início da Infecção do HIV}

A quarta classe explorou, principalmente, os desafios relacionados ao início do tratamento, como o uso dos remédios, a aceitação da sua condição sorológica e até o surgimento de psicopatologias relacionadas à descoberta da infecção pelo HIV, por exemplo, a depressão, o que pode ser ilustrado pelo seguinte relato:

Preconceito, doenças oportunistas, a medicação que levou a perda de peso, fraqueza no organismo, quando houve o início do tratamento veio uma depressão e o meu futuro não é planejado. (sexo masculino, idade entre 39 e 45 anos)

Após a primeira notificação de que estão com HIV, as pessoas geralmente enfrentam choque, negação e, até mesmo, pensamentos suicidas. Como a aceitação é um processo gradual, os indivíduos acabam sendo confrontados com o desconhecimento que eles têm de uma condição que se estende ao longo da sua vida e que vai requisitar vigilância constante. A impossibilidade de predizer com certeza quão rápida a infecção vai progredir para o estágio final, aliada à alternância entre fases de bem-estar e fases de grande malestar que podem ser seguidas por doenças incapacitantes, geram no indivíduo o abandono de suas atividades e de suas perspectivas para o futuro (Falvo, 2014).

O HIV, ao ser caracterizado como uma doença crônica, ocasiona uma série de questões relacionada tanto à vida dos pacientes quanto à vida de seus familiares no início da infecção. Nessa época, paciente e familiares têm que enfrentar vários desafios e precisam não somente se adaptar à doença, mas também conviver com o preconceito e outras situações estressantes (Brito, 2016).

Partindo disso, os profissionais de saúde têm um papel muito importante na promoção da resiliência de seus pacientes. Ao contribuir para uma visão positiva acerca do tratamento, os profissionais promovem resiliência e persistência no tratamento. Além disso, fortalecem o elo entre o paciente e sua família, gerando uma rede de apoio social, que é um dos elementos precursores de resiliência (Marques, 2012).

Indivíduos que apresentam alto índice de resiliência tendem a se envolver em menos comportamentos sexuais de risco, os quais são apontados como um dos fatores responsáveis pelo início da infecção pelo HIV (Araújo, 2014). Porém, diferentemente do que foi evidenciado em Iyokho (2015), que afirmava que os comportamentos sexuais de risco eram mais comuns entre homens que faziam sexo com outros homens do que entre pessoas heterossexuais, o presente estudo constatou maior índice de comportamentos sexuais de risco em pessoas heterossexuais.

As palavras descritivas da quarta classe foram as orientações sexuais homossexuais e/ou bissexuais (esse era o perfil das pessoas nos primeiros casos de contaminação do vírus HIV), que estão relacionadas com as dificuldades encontradas no início da infecção, seguidas por profissionais do sexo, usuários de drogas injetáveis e usuários de componentes sanguíneos, o que gerou uma falsa noção de que o vírus só acometia tipos específicos de pessoas com comportamentos específicos. Essa noção deixou as pessoas desses grupos com um status quo negativo e facilitou uma 
predisposição a fatores de riscos como doenças mentais e baixa autoestima, que são características que podem diminuir no processo de resiliência (AIDSMap, 2016).

\section{Classe 2:Aspectos Biológicos da Infecção pelo HIV}

No que compete à segunda classe, a ênfase recaiu sobre os cuidados que se deve ter em relação às doenças oportunistas, bem como o preconceito sofrido e a dificuldade em se administrar os remédios nas horas certas, o que pode ser demonstrado por esse trecho:

O preconceito é um fator complicador e atrapalha, no trabalho muitas pessoas não gostam de conviver e ficar perto de alguém que tenha AIDS, a saúde também fica mais fragilizada, são muitas limitações impostas devido a doença. (sexo masculino, idade entre 39 e 45 anos)

Nessa fala, pode-se observar as esferas da vida das pessoas (e.g., trabalho, relações interpessoais, saúde) que são afetadas pela infecção com HIV. A esfera biológica pesa muito, pois o tratamento só será eficaz se a pessoa o fizer de forma contínua, mesmo diante dos efeitos colaterais gerados pela utilização dos medicamentos, diminuindo, assim, a chance de surgirem doenças oportunistas (Bezerra, 2011).

Porém, para iniciar o tratamento, as pessoas passam por um processo que pode ser diretamente influenciado pela resiliência que surgiria por meio de fatores intrínsecos e extrínsecos. Segundo de Santis et al. (2013), após alcançarem tanto as motivações intrínsecas quanto as extrínsecas, as pessoas estariam mais dispostas a controlar a doença, o que incluiria o autocuidado físico e psicológico. Isso se daria por meio da escolha de um estilo de vida saudável, continuamente gerenciando esses aspectos e garantindo, dessa forma, uma melhor qualidade de vida.

A palavra descritiva da segunda classe foi a orientação sexual heterossexual, pelo fato de que, inicialmente, a infecção pelo HIV ser vinculada a pessoas homossexuais, ficando conhecida como a "peste gay" e gerando a ideia de que a AIDS era doença que veio para punir as expressões de uma população permissiva. Desse modo, pessoas heterossexuais que contraem o vírus do HIV acabam tendo um sofrimento maior por estarem acometidas de uma doença que seria exclusiva dos homossexuais, sofrendo mais estigmas e preconceitos (Costa, Oliveira, \& Formozo, 2012).

\section{Classe 3: Necessidade de Suporte na Infecção pelo HIV}

A classe restante é a classe três, a qual demonstra a necessidade, e até mesmo a dificuldade em se conseguir suporte após a descoberta da infecção, envolvendo mais uma vez o preconceito, a dificuldade de conseguir trabalho e a dificuldade de conviver em família, como foi exposto pelo relato a seguir:

As dificuldades são grandes em vários âmbitos seja no trabalho, família ou sociedade ainda é um tabu para a sociedade o o preconceito está muito presente nela em relação às pessoas que vivem com a AIDS houve uma mudança muito grande na minha vida. (sexo feminino, idade entre 31 e 38 anos)

Neste relato podemos encontrar as dificuldades mais comuns enfrentadas pelas pessoas que vivem e convivem com o HIV. Diante disso, pessoas que possuem uma rede de apoio social mais ampla podem desenvolver mais resiliência com o maior uso de recursos psicológicos e de proteção contra as adversidades, além de se tornarem menos propensas aos danos causados pelo preconceito e estigma social. Para a adesão ao tratamento, essa rede de apoio também é fundamental, uma vez que pode servir para que a resiliência se desenvolva na forma de "fator individual" aliado ao fator psicossocial (Araújo, 2014; Bezerra, 2015).

Outro aspecto que é muito procurado no enfrentamento de adversidades é a religiosidade, principalmente entre as mulheres. Acreditar em algo maior ajuda essas pessoas a seguir em frente e, muitas vezes, é um caminho para deixar o consumo de drogas lícitas ou ilícitas que já ocorria antes da infecção (Bezerra, 2011; Brito, 2016).

A variável descritora foi o sexo feminino, acendendo a discussão sobre o papel da mulher em nossa sociedade, que ainda é prioritariamente patriarcal e considera a mulher como alvo de submissão aos desejos masculinos. As mulheres também estão mais pretensas, biologicamente, à infecção pelo HIV, pois possuem uma maior mucosa exposta durante a relação sexual. Além disso, o esperma, no caso de parceiro masculino, possui um volume e uma concentração de vírus muito maior. Devido a esses fatores, a mulher tem um risco quatro vezes maior de ser infectada do que o homem (Paudel \& Baral, 2015).

Junto com esses motivos, as mulheres, muitas vezes, ainda enfrentam algo chamado de o "triplo perigo", pois além de terem sido infectadas pelo HIV, ainda são mães e são cuidadoras dos seus parceiros ou familiares. Dessa forma, a mulher enfrenta muito mais estigmas, preconceito e, até mesmo, abandono, simplesmente pelo fato de ser mulher e ter "empregado" comportamentos desviantes do ponto de vista da sociedade (ONUSIDA, 2014).

Ainda de acordo com esse papel feminino, muitas vezes, o homem tem o controle sobre a sexualidade, o que torna as mulheres mais submissas aos comportamentos sexuais dos parceiros, como no caso do uso de preservativos e do sexo seguro. As mulheres também estão mais expostas ao sexo conjugal forçado e estupro não conjugal, além da possibilidade de serem vítimas de abuso sexuais tanto dentro como fora da família (dos Anjos, Silva, Val, Rincon, \& Nichiata, 2012). 
Supõe-se que, por esses motivos, a palavra descritiva foi sexo feminino, uma vez que as mulheres têm sido associadas à necessidade de apoio, tanto por serem as que mais sofrem com os problemas advindos da nossa sociedade, em comparação com os homens, quanto pelo fato de, culturalmente, serem tidas como as cuidadoras dos filhos, do marido e até mesmo de outros familiares (Paudel \& Baral, 2015).

\section{Nuvem de Palavras da Resiliência}

Uma diferente forma de dispor os dados do corpus de forma gráfica consiste na Nuvem de Palavras (ver Figura 2), que agrupa e organiza as palavras em função da sua frequência, sendo possível identificar as palavras chaves centrais. No presente estudo, algumas dessas palavras foram: não, preconceito, dificuldade, doença, saber e muito. As palavras centrais estão relacionadas à visão negativa que a sociedade ainda tem sobre as pessoas que vivem com HIV, o que compreende o preconceito, a falta de oportunidade de trabalho, a necessidade de esconder sua situação sorológica para não sofrer o estigma que é associado à infecção pelo $\mathrm{HIV}$ e as dificuldades de gerenciar a doença no dia-a-dia.

\section{Análise de Similitude da Resiliência}

A análise de similitude contém as coocorrências das palavras e indicações das suas ramificações (ver Figura 3). As palavras "preconceitos", "não" e "dificuldades" aparecem como núcleos centrais, organizadoras das demais ramificações que partem dela e formam a árvore. Os termos descendentes - "doença", "dificuldade" e "há" - são os que mais apresentam conexão com o núcleo, com destaque para "dificuldade" que apresenta o maior número de palavras associadas.

A disposição das palavras em nuvem e a análise de similitude reforçam a visão negativa que ainda há sobre a infecção pelo HIV. Mesmo após mais de 30 anos desde o primeiro caso de infecção e da quebra da ideia errônea de ser uma doença pertencente apenas a determinados grupos populacionais, ainda há um estigma muito forte.

$\mathrm{Na}$ análise da nuvem, a palavra central ilustrava a necessidade de esconder o diagnóstico, ausência de apoio social, ausência de saúde e não aceitação do convívio com as pessoas que vivem com o HIV, principalmente pelo desconhecimento sobre os modos de contágio. Isso mostra a necessidade de se garantir a confidencialidade e de se gerir

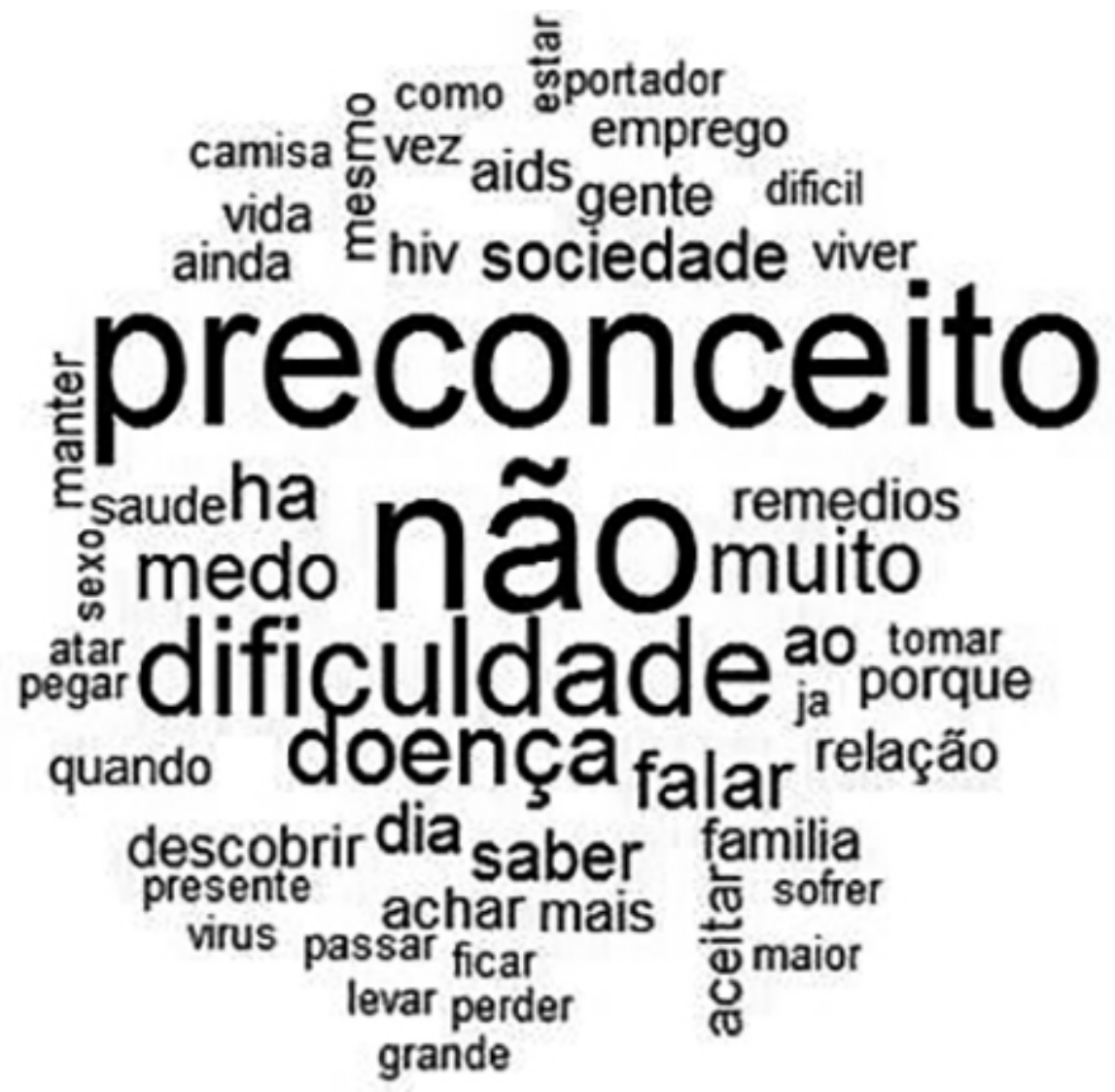

Figura 2. Nuvem de palavras da resiliência em pessoas com HIV. 


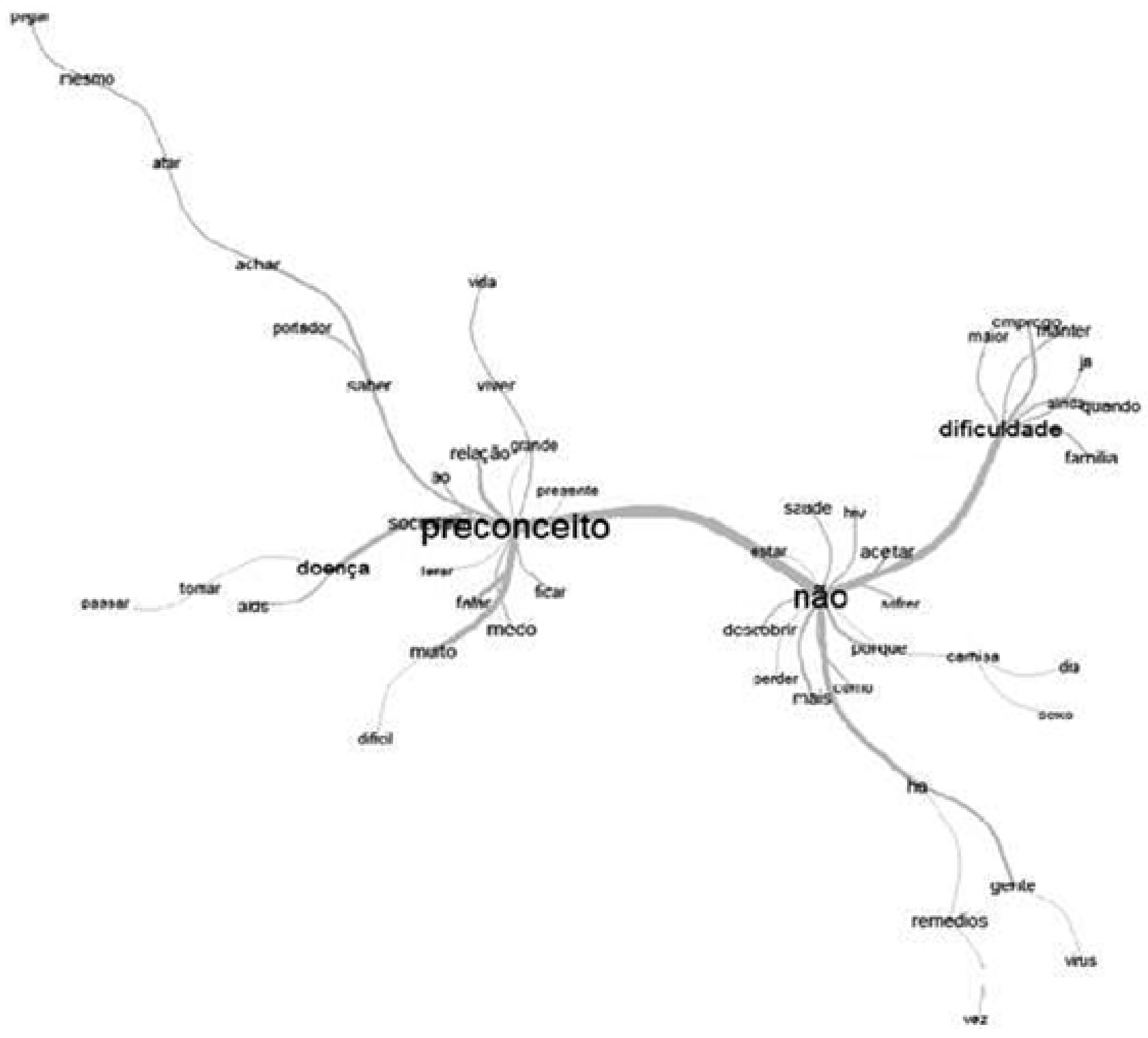

Figura 3. Análise de similitude da resiliência em pessoas com HIV.

uma rede de apoio psicossocial à pessoa que está cuidando da sua condição sorológica (Martinez \& Chakraborty, \& Committee on Pediatric AIDS, 2014).

A resiliência assume importante papel no enfrentamento do estigma contra pessoas com HIV, uma vez que pode proporcionar a autoaceitação da infecção pelo indivíduo, o que faz com que ele viva a situação do estigma social com menos danos. A vontade de viver que as pessoas desenvolvem após sua autoaceitação, a autogestão relacionada aos cuidados com a saúde (e.g., uso correto de medicamentos, dieta saudável), a responsabilidade social e um suporte social eficaz, que é fornecido principalmente pela família, mas que também pode ser obtido com grupos de apoio/convivência e organizações, são os principais fatores de construção da resiliência, fatores esses que irão contribuir diretamente para a melhoria da qualidade de vida e da saúde física e psicológica do indivíduo (Araújo, 2014; Bezerra, 2015; de Santis et al., 2013; Santos, 2016).

O conjunto de dados apreendidos nesta pesquisa, demonstrado nas diferentes formas de análise (Dendrograma, Nuvem de Palavras e Análise de Similitude), revelam as principais adversidades (resiliência) que as pessoas que vivem com HIV/AIDS apresentam em termos de preconceito e a vulnerabilidade social. Denota-se que, apesar do avanço no tratamento medicamentoso ocorrido nas últimas décadas com os antirretrovirais, o preconceito ainda acompanha a história social do HIV/AIDS, de modo que, entre os participantes desta pesquisa, a discriminação e a exclusão social foram fatores negativos atribuídos a vivência da soropositividade para o HIV. 


\section{CONSIDERAÇÕES FINAIS}

A presente pesquisa buscou identificar a resiliência entre pessoas que vivem com o HIV/AIDS e que estão em acompanhamento por profissionais de saúde e em tratamento com antirretrovirais. Os dados apreendidos entre os participantes demonstraram as principais adversidades intrínsecas à condição de viver com HIV/AIDS, tais como os estereótipos negativos, os preconceitos e a exclusão social.

A presente investigação apresenta dados relevantes no que diz respeito aos aspectos psicossociais da vivência da soropositividade para o HIV. Denota-se, ao longo das falas dos participantes, que a exclusão social e o preconceito ainda são os principais empecilhos enfrentados pelas pessoas que vivem com o HIV. Tal exclusão foi relatada principalmente no âmbito laboral, na medida em que as pessoas que vivem com HIV/AIDS têm dificuldades em conseguir trabalho, o que corrobora o preconceito explícito contra essas pessoas para o exercício da sua profissão, mesmo que seja proibido por lei no âmbito nacional.

Pode-se acrescentar, ainda, com base nos dados coletados, que a exclusão social como um fator de risco pode diminuir o fator de resiliência ao afetar, principalmente, as relações interpessoais das pessoas infectadas pelo HIV. Essas pessoas, por medo do estigma e preconceito, acabam não revelando sua condição sorológica, deixando, assim, de receber o apoio social por parte de familiares e de outras pessoas que também convivem com a infecção pelo HIV, o que é um importante fator na construção da resiliência.

Além da exclusão social, os próprios efeitos dos TARV podem influenciar o desenvolvimento da resiliência. $\mathrm{O}$ desejável é que, a despeito dos sintomas colaterais, não ocorra o abandono do tratamento (mesmo que o início deste também tenha sido citado como fator de resiliência, pois envolve questões de aceitação, mudança de hábitos, gestão do próprio tratamento), de modo a tornar possível o controle da carga viral e, consequentemente, uma melhor qualidade de vida.

Dessa forma, espera-se que o conjunto dos dados desta pesquisa possam subsidiar futuras intervenções em saúde, com o escopo de contribuir para um maior nível de resiliência. Uma resiliência mais acentuada poderia proporcionar uma qualidade de vida melhor, tanto em relação a vivência do estigma e da exclusão social, quanto no manejo dos efeitos colaterais advindos dos medicamentos antirretrovirais, proporcionando uma continuidade da vida, mesmo após a infecção pelo HIV.

Algumas limitações da presente pesquisa devem ser assinaladas. Em primeiro lugar, devido ao fato de ser um estudo qualitativo e com uma amostra clínica restrita, sugere-se que seja realizado um estudo com delineamento experimental que possa oferecer relações causais entre as variáveis, bem com o emprego de uma amostra com maior alcance, com o intuito de oferecer uma generalização dos dados para outras realidades socioculturais. Em segundo lugar, sugere-se estudos futuros com modelos explicativos que contemplem diferentes constructos psicossociais (resiliência, autoeficácia para adesão ao tratamento, estigma social, conhecimento sobre infecção pelo HIV e apoio social) de forma comparativa entre pessoas que vivem com HIV e a população em geral.

\section{REFERÊNCIAS}

Agência Aids. (2012). UNAIDS: 78 países ainda negam ou restringem entrada de estrangeiros com HIV e AIDS. Recuperado de http://agenciaaids.com.br/home/ noticias/ noticia_detalhe/18967\#.V28g2LgrLIW

AIDSMap. (2016). HIV basics. Recuperado de 2016 de http://www. aidsmap. com/hiv-basics/ HIV-AIDS/page/1412437/

Araújo, L. F. (2014). Autoeficacia, conocimento, resiliencia y preocupación por el VIH/sida: Diferencias entre infectados y no infectados por VIH (Tese de Doutorado). Recuperado de http://digibug.ugr.es/ bitstream/10481/35179/1/24460874.pdf

Araújo, L. F., Lôbo, C. J. C., Santos, J. V. O., \& Sampaio, A. V. F. C. (2017). Concepções psicossociais acerca do conhecimento sobre a AIDS das pessoas que vivem com o HIV. Revista Colombiana de Psicología, 26(2), 219-230.

Araújo, L. F, Teva, I. \& Bermúdez, M. (2015). Resiliencia en adultos Una revisión teórica. Terapia Psicológica, 33(3), 257-276.

Bezerra, M. (2011). Apoio social e resiliência no processo de adesão ao tratamento antirretroviral de moradores de rua que vivem com HIV (Dissertação de Mestrado). Recuperado de http://tede2.pucrs.br/tede2/handle/tede/732

Bezerra, S. (2015). Resiliência e qualidade de vida em pessoas que vivem com HIV/AIDS (Dissertação de Mestrado). Recuperado de http://www.uern.br/controledepaginas/ ppgss-defendidas -turma-2013/arquivos/2873sabrina_lisboa_bezerra.pdf
Bhui, K. (2014). A fine balance in the science of risk and resilience. The British Journal of Psychiatry, 204(5), 413-414.

Brito, H. L. (2016). Coping religioso, resiliência e qualidade de vida em pessoas com HIV/AIDS (Tese de Doutorado). Recuperado de http://repositorio. unb.br/handle/10482/20528

Camargo, B. V. (2005). ALCESTE: Um programa informático de análise quantitativa de dados. In A. S. P. Moreira. (Org.), Perspectivas teórico-metodológicas em representações sociais (pp. 511-539). João Pessoa: UFPB/Editora Universitária. Recuperado de http://www.laccos.com.br/pdf/Camargo 2005_alc.pdf

Castro, J. L. D. C., Santos, J. V. D. O., Araújo, L. F. D., Faro, A., Rocha, A. P. P. D., \& Reis, S. T. (2019). Representações sociais do VIH/SIDA para adolescentes: Uma abordagem estrutural. Análise Psicológica, 37(1), 15-27.

Costa, F. M., Souza, I. C., Ribeiro, Z. S., Santos, J. A., \& Carneiro, J. A. (2014). Mulheres vivendo com HIV/AIDS: Avaliação da qualidade de vida. Revista Saúde e Pesquisa, 7(3), 503-513.

Costa, T. L., Oliveira, D. C., \& Formozo, G. A. (2012). Representações sociais sobre pessoas com HIV/AIDS entre enfermeiros: Uma análise estrutural e de zona muda. Estudos e Pesquisas em Psicologia, 12(1), 242-259.

Cotian, M. S., Vilete, S., Volchan, E., \& Figueira, I. (2014). Revisão sistemática dos aspectos psicossociais, neurobiológicos, 
preditores e promotores de resiliência em militares. Jornal Brasileiro de Psiquiatria, 63(1), 72-85.

de Santis, J. P., Florom-Smith, A., Vermeesch, A., Barroso, S., \& de Leon, D. (2013). Motivacion, management, and mastery: A theory of resilience in the context of HIV infection. Journal of the American Psychiatric Nurses Association, 19(1), 36-46.

dos Anjos, R. H., D., Silva, J. A. S., Val, L. F., Rincon, L.A., \& Nichiata, L.Y. (2012). Differences between female and male adolescents regarding individual vulnerability to HIV. Revista da Escola de Enfermagem da USP, 46(4), 829-837.

Falvo, D. (2014). Human immunodeficiency virus (HIV) infection. In D. R. Falvo \& B. E. Holland (Eds.), Medical and psychosocial aspects of chronic ilness and disability (pp. 333-337). Burlington, MA: Jones \& Bartlett Learning.

Freitas, F. R. S., Santos, J. V. D. O., \& Araújo, L. F. (2019). Representaciones sociales de agentes comunitarios de salud sobre el SIDA. Perspectivas en Psicología, 16(1), 76-87.

Goldstein, T. S. (2012). Entre o conceito e a metáfora: A resiliência como abordagem do humano a partir da física dos materiais. O Mundo da Saúde, 36(2), 327-331.

Iyokho, W. O. (2015). Psycho-social resilience and risky HIV behaviors among black males who have sex with males (Tese de Doutorado). Walden University, Minneapolis, MN.

Kline, A. (2014). The effects of HIV/AIDS knowledge during adolescence: The role of this knowledge in predicting sexual behavior and outcomes. Journal American Psychiatry Nurses Association, 19, 36-46.

Lima, F., Pichelli, A., \& Silva, J. (2014). A convivência com HIV/ AIDS em mulheres soropositivas. CIAIQ2014, 2, 388-393.

Luthar, S. S., Cicchetti, D., \& Becker, B. (2000). The construct of resilience: A critical evaluation and guidelines for future work. Child Development, 71(3), 543-562.
Marques, M. A. (2012). Resiliência na situação de doenças crônicas (Trabalho de Conclusão de Curso). Recuperado de http://www.fsj.edu.br/wp-content/uploads/2013/11/ resili \% c 3\%a ancia-na-situa $\%$ c $3 \%$ a $7 \%$ c $3 \%$ a 3 o-de-doen $\%$ c3\%a7as-cr\%c3\%b4nicas.pdf

Martinez, J., Chakraborty, R., \& Committee on Pediatric AIDS. (2014). Psychosocial support for youth living with HIV. Pedriatics, 133(3), 558-562.

Martins, R. X., \& Ramos, R. (2013). Metodologia de pesquisa: Guia de estudos. Lavras: UFLA, 8-21.

Ministério da Saúde. (2018). Boletim Epidemiológico HIV/ Aids. Recuperado de http://www.aids.gov.br/pt-br/pub/2018/ boletim-epidemiologico-hivaids-2018

Oliveira, L. L., Negra, M. D., Martins, M. C. (2012). Projetos de vida de adultos jovens portadores de HIV por transmissão vertical: Estudo exploratório com usuários de um ambulatório de Infectologia. Saúde Social, 21(4), 928-939.

ONUSIDA. (2019). Informe sobre la epidemia mundial de Sida 2018. Recuperado de http://www.unaids.org

Paudel, V., \& Baral, K. (2015). Women living with HIV/AIDS (WLHA), battling stigma, discrimination and denial and the role of support groups as a coping strategy: A review of literature. Reproductive Health, 12(1), 53.

Presidência da República. (2014). Lei no 12.984, de 02/06/2014: Define o crime de discriminação dos portadores de HIV e doentes de AIDS. Diário da República 1, série $n^{\circ} 104$ (seção 1), p. 3.

Santos, F. D. R. P. (2016). Mulheres convivendo com AIDS: Fatores de risco, protetivos e resiliência (Dissertação de Mestrado). Recuperado de https://repositorio.uft.edu.br/ bitstream/11612/324/1/francisco20dimitre\%20rodrigo $\% 20$ pereira $\% 20$ santos\%20-20 disserta\% c3\%a7\%c3\%a3o. pdf 